\title{
THE CIRCULATORY CHANGES AFTER FULL THERAPEU- TIC DOSES OF DIGITALIS, WITH A CRITICAL DISCUSSION OF VIEWS ON CARDIAC OUTPUT ${ }^{1}$
}

\author{
By W. DOCK AND M. L. TAINTER
}

(From the Departments of Medicine and Pharmacology, Stanford University School of Medicine, San Francisco)

(Received for publication September 3, 1929)

Withering (1) observed that digitalis was more likely to succeed when the pulse was "feeble and intermitting" than when it was "tight and cordy." Not until the work of Cushny and Mackenzie was it known how digitalis slows and makes "more regular" the heart beats of the patients with auricular fibrillation. At present, there are still contradictory explanations of the mode of action of digitalis in diminishing the signs and symptoms of failure of the regularly beating heart.

The controversy between those who have regarded digitalis as a depressant and those who have considered it a stimulant was joined within a few years after the drug came into general use. In 1799, Ferriar (2) wrote of its "sedative power" on the heart and its "proper action in retarding the velocity of the circulation." In the same period Beddoes (3), who measured the force of the pulse stated that, "Digitalis very regularly increases the momentum of the blood." The verdict of the leading heart specialists (Hope, Stokes, Latham, Flint, Walshe) favored a belief in the theory of the sedative action until after the confirmation of Blake's (4) ${ }^{\bullet}$ report that digitalis raised arterial pressure in dogs. Continued study with perfused and intact hearts, indicated that digitalis powerfully augmented cardiac contractions, so that its position as the most effective heart stimulant was firmly established. When Sahli (5) reported the fall of blood pressure with returning compensation in digitalized cases of hypertensive heart failure, he interpreted this effect not as a sedative action, but as the

${ }^{1}$ Read before the Section on Pharmacology and Therapeutics, Eightieth Annual Session of the American Medical Association, Portland, Oregon, July 11, 1929. 
result of improved cardiac function and better circulation in the vasomotor centers. The numerous experimenters, who noted a diminished blood velocity after administering digitalis to animals, also saw a rise in arterial pressure and ascribed the reduced cardiac output to vasoconstriction rather than to cardiac depression. Texts and monographs have concerned themselves with stimulation of the heart obtained in deeply anesthetized animals with the heart exposed; they passed lightly over the direct measurements of blood-flow in animals in a more natural state.

The earlier investigations may be summarized briefly: Lenz (6) reported the flow as "sometimes smaller, sometimes greater," in digitalized animals. Kramnik (7) found that small doses of digitalis increased, while larger doses diminished the velocity of flow. M. Kaufmann (8) measured arterial and intra-auricular pressures and velocity of flow in the carotid arteries of sheep and horses. After giving digitalis the pressure rose and the rate of flow fell in the arteries, while in the auricles the pressure rose for a short time and then fell below the control level. Donaldson (9) found a diminished cardiac output with a rise of arterial pressure in frogs. Hemmeter (10) showed that ergot and digitalis both caused an increase in pressure and a decrease in carotid flow in dogs and cats. Popper (11) noted a fall in venous pressure and a rise in arterial pressure from strophanthin. Pick (12), Edmunds (13), Tigerstedt (14) and Hürthle (15), working with different species and apparatus, observed decreases in cardiac output, or velocity of flow, in large arteries of animals treated with digitalis, and ascribed it to the vasoconstrictor action of the drug or to vagal slowing of the heart.

The first carefully reasoned summary of the effect of digitalis on the circulation of normal mammals was made by Kaufmann (8). He stated that digitalis raised the arterial blood pressure, lowered the venous pressure and diminished cardiac output by constricting the arterioles, and that it diminished ventricular volume but increased the amplitude of the beats. The first (and still the largest) series of measurements of changes in cardiac output under digitalis administration was that of Tigerstedt (14). In twelve rabbits in which the initial blood pressure was higher than $50 \mathrm{~mm} . \mathrm{Hg}$, the average cardiac output per minute fell 28 per cent at the time of the maximum pressure rise of $20 \mathrm{~mm}$. Hg. The other eight rabbits had an impaired circulation with an initial pressure of less than $50 \mathrm{~mm}$.; in these the average increase in output was 18 per cent at the time of the greatest rise in pressure, i.e., $27 \mathrm{~mm}$. above the control level. This fully confirmed 
the earlier suggestions that the effects of the administration of digitalis varied with the state of the heart. That is to say, the greatest increase in cardiac output after giving digitalis occurred in depressed hearts. These observations of Kaufmann and of Tigerstedt on diminished cardiac output have been generally disregarded, but not disproved. They fit in with the vasoconstriction regularly demonstrated after large doses, and known to occur with doses as small as one-thirtieth the lethal dose of digitalis (16).

The Fick principle permits measurement of the cardiac out-put of unanesthetized animals, since it requires only the measurement of oxygen consumption and the oxygen content of arterial and mixed venous bloods (obtained by cardiac puncture). By this method the earlier observations of diminished cardiac output after digitalis administration have been confirmed by Harrison and Leonard (17), and with more uniform results by Cohn and Stewart (18). The latter correlated the diminution of cardiac output with the decrease in size of digitalized hearts, measured from roentgenograms. Harrison and Leonard, and Cohn and Stewart did not consider the rôle of the peripheral vascular changes in the decreased cardiac output; they recorded no data on arterial or venous pressure. Harrison and Leonard ascribed the changes after giving digitalis to a sedative (depressant) action on cardiac contraction. We infer that Cohn and Stewart ascribed the fall in cardiac output to a diminished filling of the ventricle due to altered diastolic tone. Neither Harrison and Leonard's theory nor the facts so far accumulated, as illustrated by the experiments of Cohn and Stewart, satisfactorily explains the effects of digitalis, since it does not consider all the known and established actions of the drug on the circulation and does not correlate the latter with factors determining cardiac output.

The factors directly governing cardiac output are heart rate, efficiency of systolic contraction (cardiac tonus in Starling's sense (19)), peripheral resistance and venous return. The last is, of course, the preponderant factor under normal conditions, since the heart, through alterations of the diastolic volume, can maintain a constant flow in spite of wide variations in rate or peripheral resistance if the venous return is constant. It is improbable, therefore, that the decreased output of the digitalized heart can be due simply to the slowing or to the rise of blood pressure which usually occurs in animals.' Studies of the dynamics of the intact heart (20), and of the isolated heart with constant, or controlled, venous and arterial pressures $(21,22,23)$, have shown that digitalis increases the efficiency and force of systole, 
although it can only increase the cardiac output provided the ventricles have become functionally inefficient due to damage from experimental procedure, or to overdistention from excessive arterial pressure or venous return. Under normal conditions in these hearts, with constant venous return, digitalis regularly diminishes the heart size but in spite of the smaller initial volume the ventricle continues to expel the same amount of blood per beat. Stated in another way, giving digitalis increases the force of systole so that a smaller residuum of blood remains in the ventricles at the end of the ejection phase. Bodo (22) suggested, on the basis of the observed effect on diastolic volume of the isolated heart, that digitalis reduced the failing heart's oxygen requirement for doing a fixed amount of work, which would indicate that the digitalis effect on tone is beneficial to the heart. The evidence of cardiac stimulation by digitalis is firmly established, but this augmentation of muscular function is not necessarily inconsistent with a diminution of cardiac output in normal animals.

Since the changes in heart rate, cardiac tonus and arterial pressure produced by the administration of digitalis are inadequate for explanation of the diminution in cardiac output, we are left with two alternative explanations; altered diastolic distensibility or altered venous return. A decrease in diastolic distensibility would diminish the filling of the ventricle and thus decrease its output. There is some evidence (24) that such a change occurs in mammalian hearts after administration of toxic doses of digitalis, thus giving plausibility to the hypothesis of Cohn and Stewart. Such a change would tend to raise venous and auricular pressures by impeding blood flow into the heart. But, instead of a rise, digitalis has been found to produce a fall of venous pressure $(8,11,25)$. This makes the alternative possibility, namely, a diminished venous return, seem the logical explanation of the diminution in cardiac output.

In view of the unsatisfactory status of current views on the diminution in cardiac output caused by digitalis, we have attempted to correlate the peripheral vascular and cardiac actions of the drug, in dogs. Such a correlation of the experimentally ascertained actions of digitalis on the heart and peripheral vessels has not been made before and would appear indispensable to a satisfactory explanation of diminished cardiac output caused by the drug. 


\section{METHODS}

Dogs were used throughout, anesthetized with $10 \mathrm{mgm}$. morphine per kilo. The mean arterial pressure was recorded with a mercury manometer, and the venous pressure with a water manometer and piston recorder joined to a cannula in the superior vena cava. Cardiac output was measured either with a Henderson cardiometer or by the Fick method (as previously described (26)). Oncometers covered with rubber dam were used to record organ volume in certain experiments. Tincture of digitalis, diluted with an equal volume of 0.9 per cent $\mathrm{NaCl}$ solution, was injected intravenously. Our tincture of digitalis had been standardized by Hanzlik's (27) pigeon-emesis method (minimum emetic dose, 25 mgm. per kilo) and by the cat assay (minimum lethal dose, $88 \mathrm{mgm}$. per kilo). With this tincture, the full therapeutic dose for man by oral administration agreed with the minimum emetic dose for pigeons (28).

\section{CIRCULATORY CHANGES}

Arterial pressure. In the various experiments in which the animals had been subjected to extensive operative procedure such as opening the abdomen or thorax, the rise in arterial pressure reached its maximum in from 5 to 25 minutes after digitalis had been administered, and return to the control level in an hour or less. The speed of fall more or less paralleled the amount of operative trauma. On the other hand, it was noteworthy that, in unoperated dogs, there was a progressive and sustained rise in pressure during two hours. We studied this phenomenon in six such dogs $(\mathrm{L} 1, \mathrm{~L} 2, \mathrm{~A} 2, \mathrm{~A} 3, \mathrm{~A} 4, \mathrm{~A} 5)$ and in two others (A1, and A8), in which only the femoral arteries had been cannulated. In one dog (A3) two tests with digitalis showed no pressor response; the results with the other seven are summarized in figure 1. The control pulse rates in all were relatively slow. The changes in mean arterial pressure, in the two dogs with cannulated arteries, showed that the systolic rise was not merely due to heightened pulse pressure from slowing of the heart. The slowing of the pulse usually was maximal in from 5 to 20 minutes after injecting the drug, while the greatest rise in blood pressure occurred in from 30 to 150 minutes after injection. The arterial pressure usually was normal in six hours, and was normal in every dog on the day after injection. This agreed with the results of previous observers $(16,31)$, namely, that a gradual and persistent rise of blood pressure is characteristic of digitalized animals. Cohn and Levy (40) observed a transient increase of 20 to $66 \mathrm{~mm}$. 
$\mathrm{Hg}$ in the arterial pressure of unanesthetized dogs when given digitalis in doses on the same weight basis used for patients.

Cardiac output. The effects of digitalis on the pulse rate, arterial and right auricular pressures and cardiac output of eight dogs that have been operated on are summarized in table 1. It is seen that



Fig. 1. Shows Prolonged Rises of Arterial Blood Pressure Produced by 20 mgm. of Digitalis Per Kroo Intravenously in Intact Dogs

- - - = average of systolic blood pressure rises in 5 dogs (L1, L2, A2, A4, A5) $+\longrightarrow++=$ the maximal, and $\mathrm{O}-\mathrm{O}=$ the minimal observed response in the series; $\Delta-\Delta=$ average mean femoral blood pressure rise in two dogs (A1, A8) with artery cannulated; $\square=$ systolic blood pressure rises in two atropinized dogs (L1 and L2).

the diminution in cardiac output was very much less immediately after injecting moderate doses of digitalis, than that observed by Cohn and Stewart, using similar doses, after two and one-half hours. With these doses there was, however, a distinct rise in arterial pressure, accompanied by a decrease in venous pressure. The decreases in cardiac output and venous pressure were in some dogs preceded by 
TABLE 1

The effects of digitalis on the circulation *

\begin{tabular}{|c|c|c|c|c|c|c|}
\hline & $\stackrel{\mathscr{E}}{\rightleftarrows}$ & 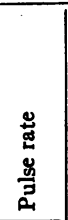 &  & 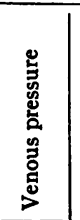 &  & Remarks \\
\hline \multirow{6}{*}{$\begin{array}{l}\text { Dog F1, } 11 \text { kgm., } \\
\text { control, minute } \\
\text { flow } 1550 \mathrm{cc} .\end{array}$} & & $\begin{array}{c}\text { per } \\
\text { min- } \\
\text { ute }\end{array}$ & $\underset{H g}{m m}$ & ${ }_{B_{2} \mathrm{O}}^{m m}$ & $\begin{array}{c}\text { per } \\
\text { cent }\end{array}$ & \multirow{5}{*}{$\begin{array}{l}\text { Control, Fick method } \\
\text { Tr. digitalis, } 0.6 \mathrm{cc} \text {. per kgm. } \\
\text { Tr. digitalis, } 0.5 \mathrm{cc} \text {. per kgm. }\end{array}$} \\
\hline & $1: 25$ & 60 & 122 & -20 & 100 & \\
\hline & $1: 30$ & & & & & \\
\hline & $\begin{array}{l}1: 34 \\
1: 40\end{array}$ & 50 & 132 & -20 & 99 & \\
\hline & $1: 44$ & 34 & 145 & -30 & 54 & \\
\hline & $\begin{array}{l}1: 40 \\
1: 43\end{array}$ & 104 & 140 & -20 & 100 & $\begin{array}{l}\text { Control, Fick method } \\
\text { Tr. digitalis, } 0.6 \mathrm{cc} \text {. per kgm. }\end{array}$ \\
\hline \multirow{6}{*}{$\begin{array}{l}\text { Dog F2, } 13 \text { kgm.; } \\
\text { control, minute } \\
\text { flow } 1940 \mathrm{cc} .\end{array}$} & $1: 50$ & 72 & 148 & -40 & 85 & \multirow{3}{*}{ Tr. digitalis, 0.5 cc. per kgm. } \\
\hline & $\begin{array}{l}2: 02 \\
2: 05\end{array}$ & 64 & 152 & -45 & 65 & \\
\hline & $\begin{array}{l}2.00 \\
2: 07\end{array}$ & 52 & 190 & -40 & 58 & \\
\hline & $2: 12$ & 156 & 205 & -10 & 49 & Irregular pulse \\
\hline & $\begin{array}{l}1: 10 \\
1: 14\end{array}$ & 68 & 124 & -30 & 100 & $\begin{array}{l}\text { Control, Fick method } \\
\text { Atropine, } 3 \text { mgm. per kgm. }\end{array}$ \\
\hline & $1: 19$ & 200 & 134 & -80 & 110 & \multirow[b]{2}{*}{ Tr. digitalis, 0.2 cc. per kgm. } \\
\hline \multirow{2}{*}{$\begin{array}{l}\text { Dog F3, } 19 \mathrm{kgm} . ; \\
\text { control, minute } \\
\text { flow } 2420 \mathrm{cc} .\end{array}$} & $1: 22$ & \multirow[b]{2}{*}{216} & \multirow[b]{2}{*}{145} & \multirow[b]{2}{*}{-100} & \multirow[b]{2}{*}{84} & \\
\hline & $\begin{array}{l}1: 26 \\
1: 32\end{array}$ & & & & & \multirow{2}{*}{ Tr. digitalis, $0.2 \mathrm{cc}$. per kgm. } \\
\hline & $1: 38$ & \multirow[t]{2}{*}{220} & \multirow[t]{2}{*}{190} & \multirow[t]{2}{*}{-75} & 58 & \\
\hline & $1: 45$ & & & & & \multirow{2}{*}{ Tr. digitalis, 0.2 cc. per kgm. } \\
\hline & $1: 53$ & 200 & 150 & -30 & 40 & \\
\hline \multirow{5}{*}{ Dog H1, 20 kgm. } & $2: 15$ & 190 & 60 & +80 & 100 & \multirow{2}{*}{$\begin{array}{l}\text { Control, cardiometer } \\
\text { Tr. digitalis, } 0.1 \text { cc. per kgm. }\end{array}$} \\
\hline & $\begin{array}{l}2: 18 \\
2: 22\end{array}$ & 180 & 90 & +75 & 108 & \\
\hline & $2: 28$ & 188 & 65 & +80 & 113 & \multirow{3}{*}{ Tr. digitalis, 0.3 cc. per kgm. } \\
\hline & $2: 30$ & & & & & \\
\hline & $2: 35$ & 160 & 90 & +70 & 86 & \\
\hline \multirow{4}{*}{ Dog H2, $18 \mathrm{kgm}}$. & $\begin{array}{l}2: 30 \\
2 \cdot 31\end{array}$ & 196 & 105 & +95 & 100 & \multirow{4}{*}{$\begin{array}{l}\text { Control, cardiometer } \\
\text { Tr. digitalis, } 0.5 \text { cc. per kgm. } \\
\text { Tr. digitalis, } 0.2 \text { cc. per kgm. }\end{array}$} \\
\hline & $2: 37$ & 192 & 116 & +95 & 106 & \\
\hline & $2: 40$ & & & & & \\
\hline & $2: 48$ & 168 & 128 & +90 & 82 & \\
\hline
\end{tabular}




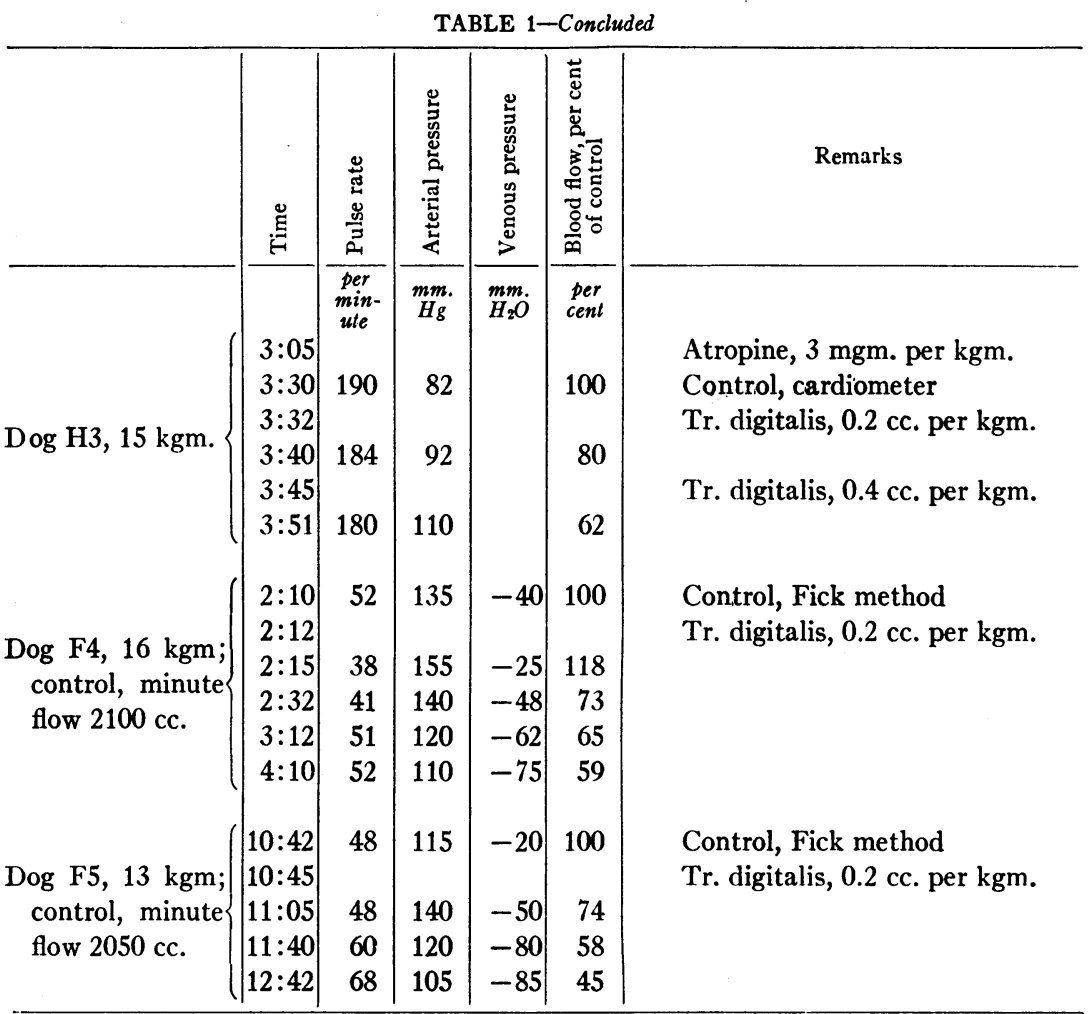

* The first six experiments deal with immediate effects of large and repeated doses, the last. two with progressive changes following one full therapeutic dose. All doses were administered intravenously.

transient increases in both output and pressure (F4, F5). Typical changes are illustrated in figures 2,3 and 4 . With toxic doses of digitalis, it was possible to produce an immediate striking rise in blood pressure and diminution in cardiac output, but usually the slowing of the pulse was very great so that the stroke volume and venous pressure were but little diminished. With such doses there was also a terminal rise in venous pressure due to toxic heart failure. In the experiments in which output was measured with the cardiometer $(\mathrm{H} 1, \mathrm{H} 2, \mathrm{H} 3)$, the initial pulse rates were rapid, but there were some $(\mathrm{H} 1, \mathrm{H} 2)$ transient increases in cardiac output, immediately after the first dose of the drug. This is illustrated in figure 5. Atro- 
pine, in doses sufficient to paralyze the vagi, did not alter the responses to digitalis (F3, H3). When the heart had become rapid or irregular from toxic doses and the blood pressure had reached excessively high levels, a rise in venous pressure occurred although the cardiac output was minimal (F2, F3).

Since the decrease in cardiac output occurred simultaneously with a fall in venous pressure and a rise in arterial pressure, the cause of the diminished output was attributed to peripheral vascular changes.

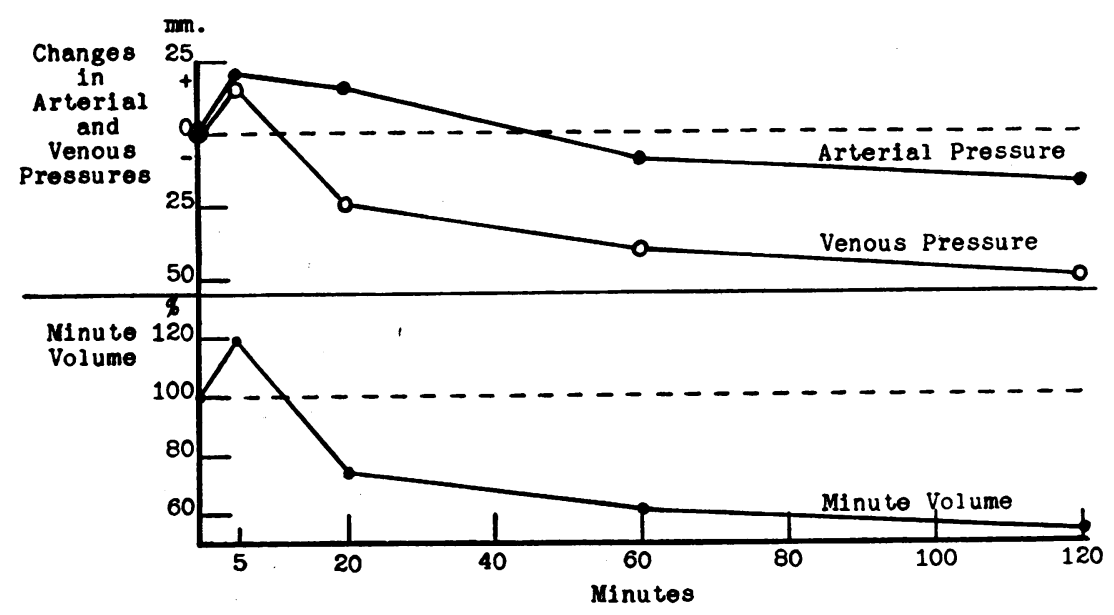

Fig. 2. Showing the Effect of One Full Therapeutic Dose (20 mgm. per Kgm.) of Digitalis on the Arterial Pressure (in Millimeters of Mercury) Venous Pressure (in Millimeters of Water), and Volume Flow of Blood THROUGH THE Lungs OF THE Dog

Based on data from dogs F4 and F5, table 1

The gradual development of an altered circulatory state is shown by a comparison of the decreases of 10 to 20 per cent in output, seen in five to ten minutes after injecting large doses, with the 40 to 60 per cent decreases present in Cohn and Stewart's observations made after two and one-half hours and in our own, on dogs F4 and F5, made after two hours. The diminished venous pressure may have been either the direct result of peripheral vasoconstriction, or the result of diminution of the effective volume of the blood. We, therefore, recorded 
the volumes of the spleen, leg and liver with the view of correlating the vascular responses with changes in cardiac output and of obtaining evidence of an altered distribution of blood.

Changes in peripheral organ volume. In two morphinized dogs, L1, L2, whose spleens had at operation been outlined with silver clips several weeks previously, we followed the changes in splenic and diastolic-heart sizes, observed roentgenographically, and the systolic



Fig. 3. Shows the Effect of Digitalis on Arterial and Venous Pressures

Dog F5, weighed $13 \mathrm{kgm}$. The control cardiac output (Fick method) was 2050) cc. At $A$, digitalis, $20 \mathrm{mgm}$. per kilogram, was injected intravenously; $B$, two minutes later shows the beginning of the rise in arterial pressure and the trans ent increase in venous pressure; $C$, twenty minutes later, the cardiac output diminished to $1520 \mathrm{cc}$. while the arterial pressure is still elevated, and the venous pressure diminished. The curve of the venous pressure is redrawn.

blood pressures and pulse rates for a period of two hours after therapeutic doses of digitalis. At intervals of one week, control observations were made on the effects of equivalent doses of alcoholic saline solutions and also of digitalis after large doses of atropine. The results during the first two hours are presented in figure 6 in the form of curves showing percentage changes in area of anterior projection from the 
control areas. The changes in both dogs were practically the same, so that only the average values are shown in the figure.

It is seen that the spleen increased in size about 20 per cent immediately after therapeutic doses of digitalis, and that an increase of $\mathbf{1 0}$

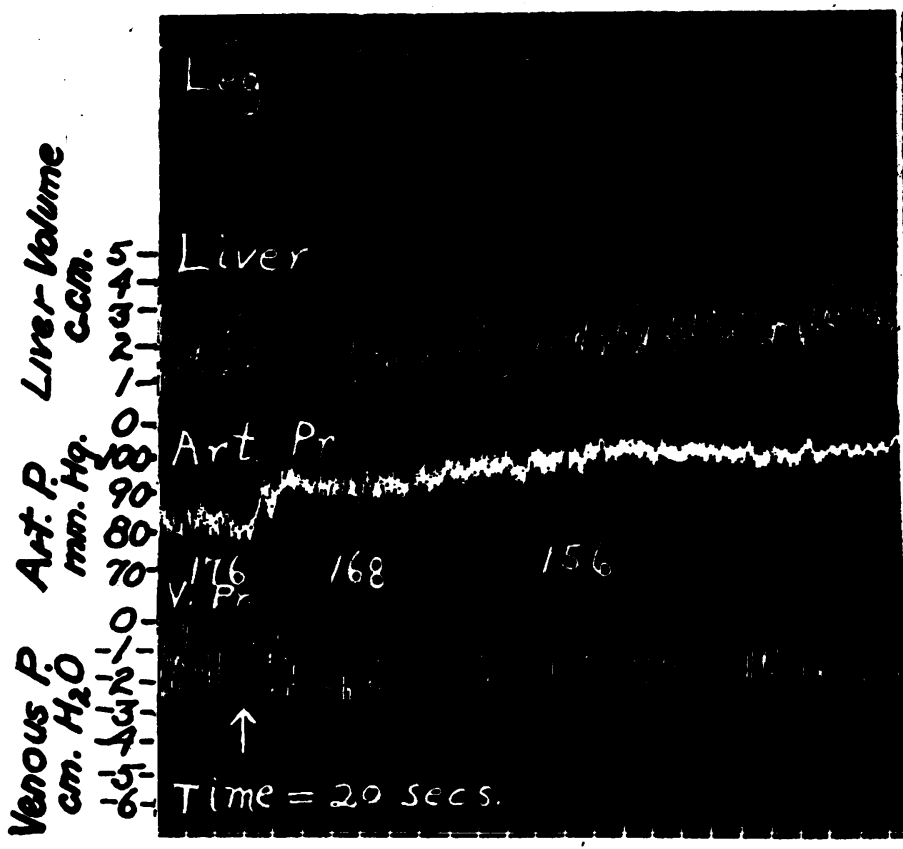

A

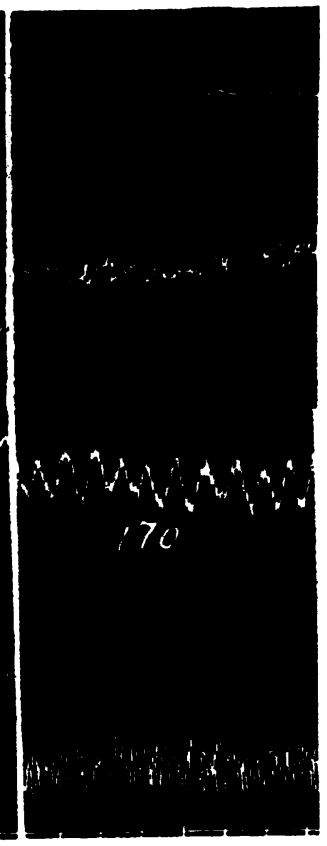

8

Fig. 4. Shows the Effects of Digitalis on Venous and Arterial Pressures AND LIVER- AND LEG-VolumeS

Dog L3, $15 \mathrm{kgm}$. At $A, 20 \mathrm{mgm}$. per kilo of digitalis was injected intravenously; between $A$ and $B$, the same dose was repeated; $B, 25$ minutes after $A$ and 5 minutes after the second injection, shows progressive constriction of the leg, increase in volume of the liver, rise of arterial, and fall of venous pressure. The curve of the venous pressure is redrawn.

per cent was still present at the end of two hours. Atropine also produced a marked dilatation of the spleen so that digitalis given thereafter produced only a small additional increase in size. That these effects were not due to the alcohol in the tincture was shown by the control alcohol injections, to which the spleen gave little dilator re- 


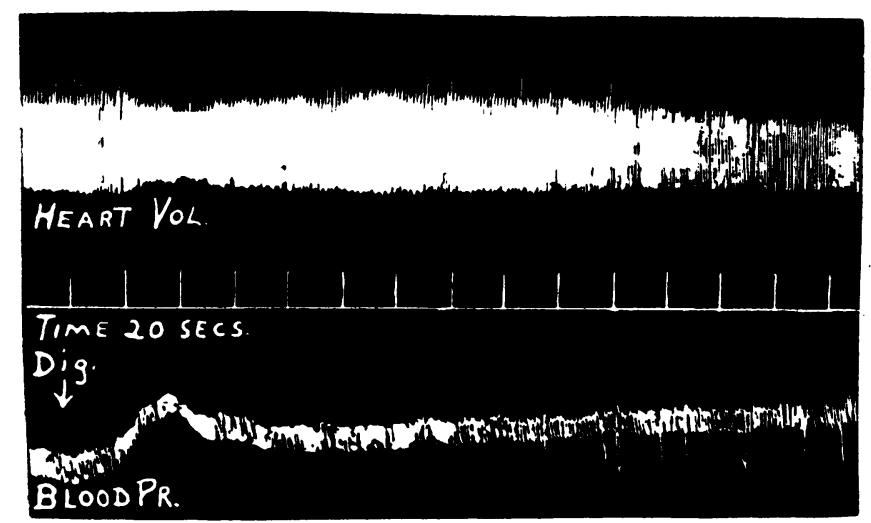

Fig. 5. Showing the Effects of Giving Digitalis on Arterial Pressure and Stroke Volume, Which Was Recorded with a Cardiometer

Dog H3, weighing $15 \mathrm{kgm}$.; was previously atropinized and received $20 \mathrm{mgm}$. of digitals per kgm. The arterial pressure rose from 86 to $112 \mathrm{~mm}$. Hg. The pulse rate remained unchanged.

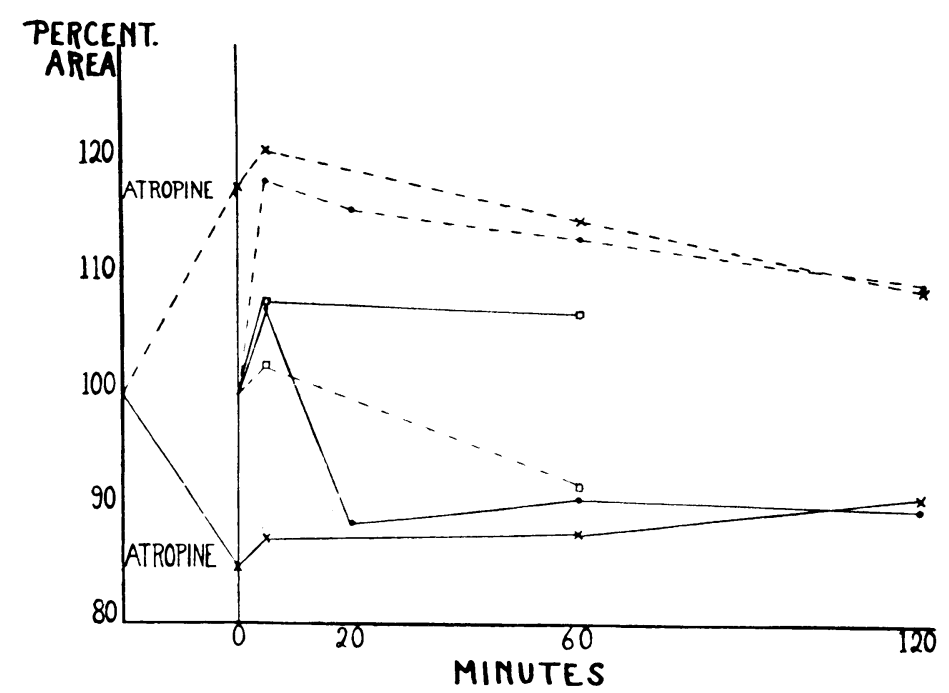

Fig. 6. Shows the Changes in Sizes of the Heart and Spleen as Observed

Roentgenographically, Showing Percentage Changes from the

Control Areas, in the Areas of the Anterior Projection

The solid lines indicate diastolic heart areas and the broken lines, splenic areas; $\longrightarrow-\bullet=$ digitalis $20-30 \mathrm{mgm}$. per kilo, $\times-\longrightarrow \times=$ same dose digitalis after atropine $2 \mathrm{mgm}$. per kilo, and $\square-\square=$ control alcohol injection of equivalent dose. 
sponse. In the same experiments, the decrease in heart size after giving digitalis was confirmed, and found to persist beyond the twohour period. of observation. It was preceded by a small transient increase in size due apparently to the alcohol in the tincture. The administration of atropine also, as would be expected from the development of tachycardia, markedly diminished the cardiac volume, so that digitalis was able to produce no further decrease.

In four curarized dogs, (L3 to L6), changes in the volume of liver lobes were recorded simultaneously with those in the arterial pressure, the venous pressure and the leg ( $\mathrm{L} 3$ and $\mathrm{L} 6$ ) or the intestinal volume (L4 and L5). The results were not altogether satisfactory, since the pulse rates in the animals prepared in this way were rapid, and the marked slowing produced by giving digitalis tended to minimize the fall in venous pressure. In one animal, the venous pressure rose. As can be seen in figure 4, there were decreases in leg volume after digitalization, with simultaneous increases ( 3 to 5 per cent) in volume of the liver in all experiments. These increases were gradual and progressive for the relatively short period during which such preparations remained in satisfactory condition. Probably, the state of the circulation in the curarized, deeply anesthetized dogs which had been operated on was not the same as in normal animals. They may be significant, however, for the development of diminution in cardiac output after the injection of digitalis. The increase in liver volume was particularly suggestive, for this indicated a pooling of the blood in this viscus due to diminished outflow as the result of hepatic vein constriction. The constriction of these veins, which are richly endowed with smooth muscle, is strictly consistent with the arterial constrictions in the leg and intestine, and would result in lowered venous pressure. ${ }^{2}$ The constriction of liver veins by digitalis has been demonstrated by Lampe (29) and confirmed by us (30).

\section{DISCUSSION}

In brief, the action of full therapeutic doses of digitalis on the circulation of normal dogs may be summarized as follows: There is an

2 The suggestion of testing the reaction of the liver and the explanation of its possible rôle in digitalis action was offered to us by Dr. Hanzlik. 
immediate rise in arterial pressure, with slowing of heart rate due to vagus stimulation. Arterial pressure continues to rise for half an hour or longer. In some instances there is a transient rise in venous pressure. The fall in venous pressure begins within 5 minutes and with it there is a diminution in cardiac output, which is progressive with the progressive fall in venous pressure and heart volume during two hours or more. Excessive slowing of the pulse rate tends to raise venous pressure and output per beat and thus minimizes or prevents fall in venous pressure from reduced return flow. The spleen and liver increase in volume after the administration of digitalis, and the resulting accumulation of blood in these and possibly other abdominal viscera reduces the venous return to the heart, accounting for the diminished cardiac output. In animals which have been operated on the phenomena are like those in the unoperated, save that the rise in arterial pressure is less marked and of shorter duration. The cardiac output remains low for several days (18), but in our observations arterial pressure returned to normal within 24 hours. We are unable to state whether, when arterial pressure has returned to normal, the venous pressure continues to be low.

That digitalis action on the peripheral circulation produces a diminished cardiac output in normal dogs may have a direct bearing on digitalis action in man. There is some evidence that even small doses of digalen or strophanthin injected intravenously, produce a slight and transient rise of blood pressure in man $(32,33)$ although oral administration causes no rise and in some individuals (28) a fall. It may be that the diminished cardiac output of digitalized human subjects (34), although less marked and less well sustained than that of the dog, is due to the same mode of action of the drug. Whether such a fall in venous return occurs or is significant in heart failure is not known. When compared with the tonic action of digitalis on the ventricular muscle this peripheral action may be unimportant. Both tend to lower venous pressure, but the ventricular effect is to increase the cardiac output when it is abnormally low. Studies of blood flow in heart failure $(36,37)$ indicate that, even in slight decompensation, the effect of digitalis is to increase the blood-flow if as is usually the case, the cardiac output has fallen to a subnormal volume. Kininmonth (35) found an average increase in stroke volume of 74 per cent 
on giving digitalis to a number of decompensated cardiac patients, but the methods available for these studies can not be regarded as giving correct quantitative results. The diminished cardiac output after taking digitalis might be of value in those conditions where blood flow is abnormally rapid. However, clinical experience with the use of the drug in such conditions, as for example in fevers, anemias and hyperthyroidism, leads us to believe that giving digitalis is far less effective here than it is in the relief of heart failure with reduced blood flow and regular rhythm $(38,39)$.

\section{SUMMARY AND CONCLUSIONS}

1. A critical review has been made of the older and current views of the actions of digitalis on the circulation and an attempt has been made, by experiments on dogs, to correlate its influence on the heart and peripheral vessels with diminution in cardiac output.

2. Previous studies, by many observers, have shown that digitalis is a very effective heart stimulant and increases the efficiency of systolic contraction, while recent observations on normal men and animals have indicated that the drug diminishes cardiac output.

3. In our own experiments in dogs a fall of venous pressure regularly accompanied the diminished cardiac output following a full therapeutic dose of digitalis. This is convincing evidence that the change in blood flow was a result of peripheral, and not cardiac, actions of the drug. These facts are in agreement with the generally accepted view that the output of the normal heart is governed largely by the venous return.

4. Following a single therapeutic intravenous dose of digitalis, there was a gradual rise of blood pressure, sometimes sustained during several hours in animals which had not been operated on, and simultaneously there were constriction of the vessels of the skin and intestine, and an increase in the volume of the liver and spleen, due to hepatic vein constriction and to a pooling of blood in these viscera. Consequently, these changes must have resulted in the diminished venous return to the heart, and a diminished output and heart size.

5. The work of previous investigators has shown that the heart contracts with increased efficiency after therapeutic doses of digitalis, but that the effect on cardiac output varies with the functional 
state of the circulation. The action of the drug, in man, probably varies in the same way, i.e., the output of the normal heart is reduced, but, in such pathological states as heart failure with passive hyperemia, digitalis would tend to increase the cardiac output and to restore the venous pressure to a normal level.

\section{BIBLIOGRAPHY}

1. Withering, W., An Account of the Foxglove and Some of Its Medical Uses. Birmingham, 1785, p. 189.

2. Ferriar, J., An Essay on the Medical Properties of the Digitalis Purpurea or Foxglove. Manchester, 1799. Abstract Ann. Med., 1800, v, 146.

3. Beddoes, T., Observations on the Medical and Domestic Management of the Consumptive. On the Powers of Digitalis Purpurea, and on Cure of Schrophula. O. Penniman and Co., Troy, 1803.

4. Blake, J., Edin. Med. and Surg. J., 1839, li, 330. Observations on the Physiological Effects of Various Agents Introduced into the Circulation, as Indicated by the Haemadynamometer.

5. Sahli, Verh. d. Cong. f. Inn. Med., 1901, xix, 45. Herzmittel und Vasomotorenmittel.

6. Lenz, E., Inaug. Dissert., Dorpat, 1853. Abstract in Schmidt's Jahrbuch der gesamt. Med., 1854, lxxxii, 9. Ueber das Verhältniss zwischen der Frequenz des Pulses, dem Seitendrucke des Blutes und der Stromgeschwindigkeit desselben.

7. Kramnik, Moskauer Pharmac. Arbeiten. Abstract in Jahresber. ü. d. Leist. und Fortschr. gesamt. Med., 1876, i, 433. Blutgeschwindigkeit und Temperatur nach der Digitaliseinwirkung.

8. Kaufmann, M., Rev. d. Med., 1884, iv, 381. Effets physiologiques de la digitaline amorphe.

9. Donaldson, H. H. and Stevens, L. T., J. Physiol., 1884, iv, 165. The Influence of Digitaline on the Work of the Heart and on the Flow Through the Blood Vessels.

10. Hemmeter, J. C., Med. Record, 1891, xl, 292. On the Effects of Certain Drugs on the Velocity of the Blood-Current.

11. Popper, J., Ztschr. f. klin. Med., 1889, xvi, 97. Ueber die physiologische Wirkung des Strophantins.

12. Pick, F., Arch. f. exp. Path. u. Pharm., 1899, xlii, 399. Ueber Beeinflussung der ausströmenden Blutmenge durch die Gefässweite ändernde Mittel.

13. Edmunds, C. W., Am. J. Physiol., 1907, xviii, 129. The Influence of Digitalis, Strophanthus and Adrenalin upon the Velocity of the Blood Current.

14. Tigerstedt, C., Skand. Archiv. Physiol., 1908, xx, 115. Zur Kenntniss der Einwirkung von Digitalis und Strophantus auf den Kreislauf. 
15. Hürthle, K., Arch. f. d. ges. Physiol., 1915, \&lxii, 338. Ueber die Aenderung der Strompulse unter dem Einfluss vasokonstriktorischer Mittel.

16. Joseph, D. R., Arch. f. exp. Path. u. Pharm., 1913, lxxiii, 81. Untersuchungen über die Herz- und Gefässwirkungen kleiner Digitalisgaben bei intravenöser Injektion.

17. Harrison, T. R. and Leonard, B. W., J. Clin. Invest., 1926, iii, 1. The Effect of Digitalis on the Cardiac Output of Dogs and Its Bearing on the Action of the Drug in Heart Disease.

18. Cohn, A. E. and Stewart, H. J., J. Clin. Invest., 1928, vi, 53. The Relation between Cardiac Size and Cardiac Output per Minute Following the Administration of Digitalis in Normal Dogs.

19. Starling, E. H. and Visscher, M. B., J. Physiol., 1927, lxii, 243. The Regulation of the Energy Output of the Heart.

20. Wiggers, C. J. and Stimson, B., J. Pharm. and Exp. Therap., 1927, xxx, 251. Studies on the Cardiodynamic Action of Drugs. III. The Mechanism of Cardiac Stimulation by Digitalis and g-Strophanthin.

21. Bijlsma, U. G. and Roessingh, M. J., Arch. f. exp. Path. u. Pharm., 1922, xciv, 235. Die Dynamik des Säugetierherzens unter dem Einfluss von Stoffen der Digitalisgruppe.

22. Bodo, R., J. Physiol., 1928, lxiv, 365. The Effect of "Heart Tonics" and other Drugs upon the Heart Tone and Coronary Circulation.

23. Anitschkow, S. W. and Trendelenburg, P., Deutsch. med. Wchnschr., 1928, liv, 1672. Die Wirkung des Strophanthins auf das suffiziente und auf das insuffiziente Warmblüterherz.

24. Eismayer, G. and Quincke, H., Arch. f. exp. Path. u. Pharm., 1928, cxxxvii, 362. Zum Tonusproblem des Herzmuskels.

25. Yokota, M., Tohoku J. Exp. Med., 1923, iv, 23. Die Wirkung der Arnzeimittel auf den Blutdruck.

26. Harrison, T. R., Dock, W. and Holman, E., Heart, 1924, xi, 337. Experimental Studies in Arterio-Venous Fistulae; Cardiac Output.

27. Hanzlik, P. J., J. Pharm. Exp. Therap., 1929, xxxv, 363. A New Method of Estimating the Potency of Digitalis: Pigeon-Emesis.

28. Hanzlik, P. J. and Stockton, A. B., J. Pharm. Exp. Therap., 1929, xxxv, 393. Results with the Pigeon-Emesis Method of Estimating the Probable Therapeutic Dose of Digitalis.

29. Lampe, W. and Méhes, J., Arch. f. exp. Path. u. Pharm., 1926, cxvii, 115. Die Beeinflussung der Libergefässe durch Strophanthin und Digitalis glykoside.

30. Tainter, M. L. and Dock, W., J. Clin. Invest., 1930, June, (In press). Further Observations on the Circulatory Actions of Digitalis and Strophanthus with Special Reference to the Liver, and Comparisons with Histamine and Epinephrine.

31. Schemensky, W., Arch. exp. Path. u. Pharm., 1923, c, 367. Untersuchungen über die Herz- und Gefässwirkungen kleiner Digitoxingaben bei intravenöser Injektion. 
32. Eychmüller, H., Berlin Klin: Wchnschr., 1909, xlvi, 1677. Ueber die Herzund Gefässwirkung des Digalens bei gesunden und kranken Menschen.

33. Vagt, O., Med. Klink, 1909, v: 1858, 1895, 1938. Ueber die Herz- und Gefässwirkung des Strophanthins bei gesunden und kranken Menschen.

34. Burwell, C. S., Neighbors, D. and Regen, E. M., J. Clin. Invest., 1927, iv, 431. The Effect of Digitalis upon the Pulse Rate and Circulatory Minute Volume of Normal Human Subjects.

35. Kininmonth, J. G., Quart. J. Med., 1928, xxi, 277. The Circulation Rate in Some Pathological States, with Observations on the Effect of Digitalis.

36. Lauter, S. and Baumann, H., Klin. Wchnschr., 1929, viii, 263. Zur Theorie der Herzinsuffizienz und der Digitaliswirkung.

37. Weiss, S. and Blumgart, H. L., J. Clin. Invest., 1929, vii, 11. The Effect of Digitalis Bodies on the Velocity of Blood Flow Through the Lungs and on Other Aspects of the Circulation.

38. Christian, H. A., Am. J. Med. Sci., 1919, clvii, 593. Satisfactory Effects in Cardiac Cases with Regular Pulse Rates.

39. Luten, D., Arch. Int. Med., 1924, xxxiii, 251. Clinical Studies of Digitalis. I. Effects Produced by the Administration of Massive.Doses to Patients with Normal Mechanism.

40. Cohn, A. E. and Levy, R. L., Proc. Soc. Exp. Biol. Med., 1920, xvii, 160. The Effect of Therapeutic Doses of Digitalis on the Contraction of Heart Muscle. 